$\mathrm{p}=0.007$ ). Hoping not to become infected with COVID-19 and to maintain the same health status, were especially those who were older ( 3.6 vs $3.4 p=0.018$ ) without anxiety ( 3.4 vs 3.6 at risk, $p=0.005$ ), and without depression ( 3.6 vs 3.4 at risk, $p=0.006)$. Another important hope was the availability of a treatment or vaccine for COVID-19, which was important for patients experiencing better well-being ( 3.3 vs 3.0 with worse well-being, $p<0.001$; Figure 1 ).

Conclusion: The outstanding COVID-19-related fear expressed by European patients with RMDs was its impact on healthcare, while the greatest hope was to be able to continue treatment. Younger patients reported more fears while older patients were more hopeful. Those receiving biologics had greater fears and hopes associated with their treatment. In addition, patients at risk of mental disorders presented greater fears and less hopes.

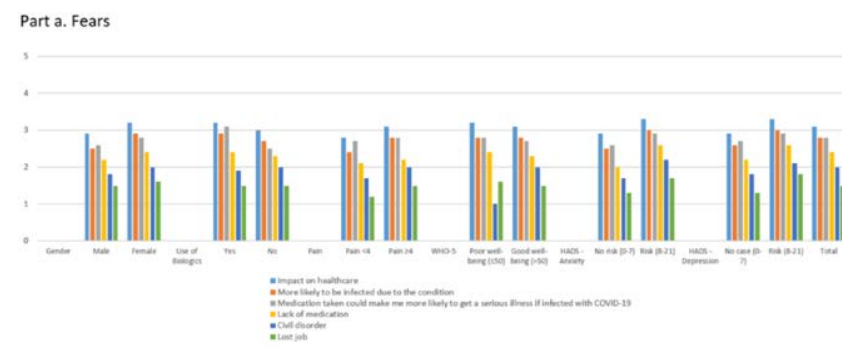

Part b. Hopes

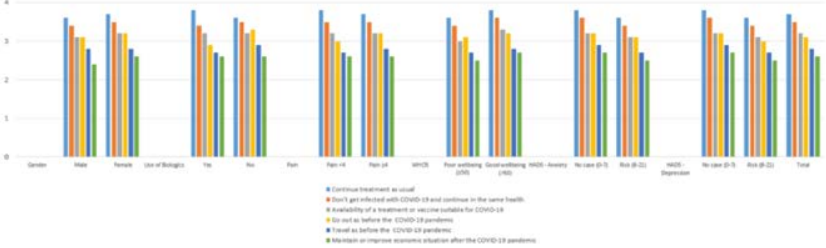

Figure 1. Fears and Hopes of REUMAVID participants

Acknowledgements: This study was supported by Novartis Pharma AG. We would like to thank all patients that completed the survey as well as all of the patient organisations that participated in the REUMAVID study including: the Cyprus League Against Rheumatism (CYPLAR) from Cyprus, the Association Française de Lutte Anti-Rhumatismale (AFLAR) from France, the Hellenic League Against Rheumatism (ELEANA) from Greece, the Associazione Nazionale Persone con Malattie Reumatologiche e Rare (APMARR) from Italy, the Portuguese League Against Rheumatic Diseases (LPCDR), from Portugal, the Spanish Federation of Spondyloarthritis Associations (CEADE), the Spanish Patients' Forum (FEP), UNiMiD, Spanish Rheumatology League (LIRE), Andalusian Rheumatology League (LIRA), Catalonia Rheumatology League and Galician Rheumatology League from Spain, and the National Axial Spondyloarthritis Society (NASS), National Rheumatoid Arthritis (NRAS) and Arthritis Action from the United Kingdom.

Disclosure of Interests: Marco Garrido-Cumbrera: None declared, Helena Marzo-Ortega Speakers bureau: AbbVie, Biogen, Celgene, Janssen, Lilly, Novartis, Pfizer, Takeda and UCB, Consultant of: AbbVie, Celgene, Janssen, Lilly, Novartis, Pfizer and UCB, Grant/research support from: Janssen and Novartis, Laura Christen Employee of: Novartis Pharma AG, Loreto Carmona: None declared, José Correa-Fernández: None declared, Sergio Sanz-Gómez: None declared, Pedro Plazuelo-Ramos: None declared, Dale Webb Grant/research support from: AbbVie, Biogen, Janssen, Lilly, Novartis and UCB., Clare Jacklin Grant/ research support from: Abbvie, Amgen, Biogen, Eli Lilly, Gilead, Janssen, Pfizer, Roche, Sanofi \& UCB, Shantel Irwin: None declared, LAURENT GRANGE: None declared, Souzi Makri Grant/research support from: Novartis, GSK and Bayer., Elsa Mateus Grant/research support from: Lilly Portugal, Sanofi, AbbVie, Novartis, Grünenthal S.A., MSD, Celgene, Medac, Janssen-Cilag, Pharmakern, GAfPA., Serena Mingolla: None declared, KATY ANTONOPOULOU: None declared, Victoria Navarro-Compán Grant/research support from: Abbvie, BMS, Janssen, Lilly, MSD, Novartis, Pfizer, Roche, and UCB DOI: 10.1136/annrheumdis-2021-eular.2405

\section{AB0677 GENDER DIFFERENCES ON THE IMPACT OF THE COVID-19 PANDEMIC AND LOCKDOWN IN PATIENTS WITH RHEUMATIC DISEASES. RESULTS FROM THE REUMAVID STUDY (PHASE 1)}

M. Garrido-Cumbrera ${ }^{1}$, H. Marzo-Ortega ${ }^{2,3}$, L. Christen ${ }^{4}$, L. Carmona ${ }^{5}$, J. Correa-Fernández ${ }^{1}$, S. Sanz-Gómez ${ }^{1}$, P. Plazuelo-Ramos ${ }^{6}$, S. Makri ${ }^{7}$,
E. Mateus ${ }^{8,9}$, S. Mingolla ${ }^{10}$, K. Antonopoulou ${ }^{11}$, L. Grange ${ }^{12,13}$, C. Jacklin ${ }^{14}$, D. Webb ${ }^{15}, \mathrm{~S}$. Irwin ${ }^{16}$, V. Navarro-Compán ${ }^{17}$ on behalf of REUMAVID working group. ${ }^{1}$ Universidad de Sevilla, Health \& Territory Research (HTR), Seville, Spain; ${ }^{2}$ University of Leeds, Leeds Institute for Rheumatic and Musculoskeletal Medicine, Leeds, United Kingdom; ${ }^{3}$ Leeds Teaching Hospitals Trust, NIHR Leeds Biomedical Research Centre, Leeds, United Kingdom; ${ }^{4}$ Novartis Pharma AG, Patient Engagement, Basel, Switzerland; ${ }^{5}$ Institute for Musculoskeletal Health, InMusc, Madrid, Spain; ${ }^{6}$ Spanish Federation of Spondyloarthritis Associations (CEADE), Presidency, Madrid, Spain; ${ }^{7}$ Cyprus League Against Rheumatism (CYPLAR), Management, Nicosia, Cyprus; ${ }^{8}$ Liga Portuguesa Contra as Doenças Reumáticas (LPCDR), Management, Lisbon, Portugal; ${ }^{9}$ NOVA Medical School, Comprehensive Health Research Centre (CHRC), Lisbon, Portugal; ${ }^{10}$ Italian National Association of People with Rheumatic and Rare Diseases (APMARR), Communication, Bari, Italy; ${ }^{11}$ Hellenic League Againts Rheumatism (ELEANA), Management, Athens, Greece; ${ }^{12}$ French League Against Rheumatism (AFLAR), Management, Grenoble, France; ${ }^{13}$ Centre Hospitalier Universitaire de Grenoble, Rheumatology, Grenoble, France; ${ }^{14}$ National Rheumatoid Arthritis Society (NRAS), Management, London, United Kingdom; ${ }^{15}$ National Axial Spondyloarthritis Society (NASS), Management, London, United Kingdom; ${ }^{16}$ Arthritis Action, Management, London, United Kingdom; ${ }^{17}$ Hospital Universitario La Paz, IdiPaz, Madrid, Spain

Background: The COVID-19 pandemic has impacted health, lifestyle, treatment and healthcare of European patients with rheumatic and musculoskeletal dis eases (RMDs).

Objectives: The aim is to evaluate gender differences on the impact of the first wave of the COVID-19 pandemic in the wellbeing, life habits, treatment, and healthcare access of European patients with RMDs.

Methods: REUMAVID is an international collaboration led by the Health \& Territory Research at the University of Seville, together with a multidisciplinary team including patient organisations and rheumatologists. This cross-sectional study consisting of an online survey gathering data from 1,800 patients with a diagnosis of 15 RMDs, recruited by patient organisations in Cyprus, France, Greece, Italy, Portugal, Spain, and the United Kingdom during the first phase of the pandemic (April-July 2020). Mann-Whitney and $\chi^{2}$ tests were used to analyse differences between gender regarding sociodemographic characteristics, life style, treatment, healthcare, and patient-reported outcomes.

Results: 1,797 patients were included in this analysis. $80.2 \%$ were female and a mean age of 52.6 years. The most common diagnosis was inflammatory

Table 1. Bivariate analysis by gender ( $N=1,797$ unless specify)

\begin{tabular}{lll} 
Mean \pm SD or $n(\%)$ & P- value \\
\hline Male & Female \\
$(\mathrm{N}=355)$ & $(\mathrm{N}=1,442)$
\end{tabular}

Sociodemographic characteristics Disease

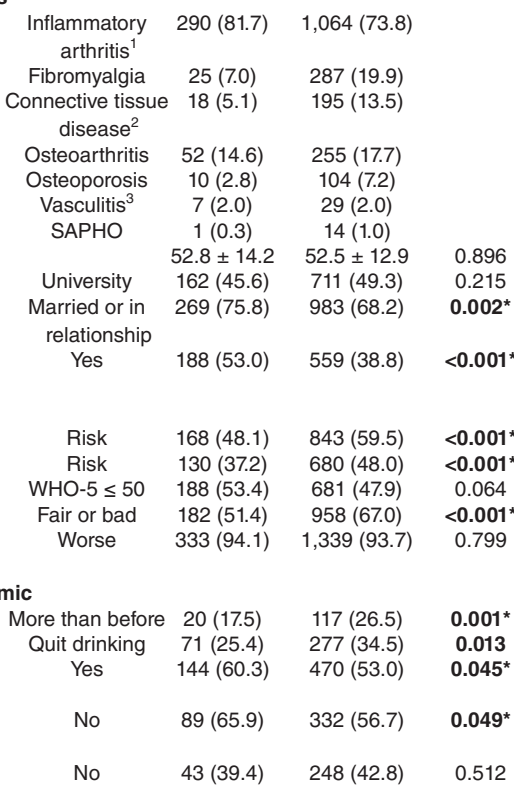

Age, years

Educational level

Marital status

Member of a Patient organisation, $\mathrm{N}=1,795$

Patient-reported outcomes

HADS Anxiety, $\mathrm{N}=1,766$

HADS Depression, $\mathrm{N}=1,766$

Wellbeing, $\mathrm{N}=1,774$

Self-perceived health, $\mathrm{N}=1,783$

Change in health status during

COVID-19 pandemic, $\mathrm{N}=1,783$

Life style during COVID-19 pandemic

Smoking, $\mathrm{N}=555$

Alcohol consumption, $\mathrm{N}=1,083$

Physical activity, $\mathrm{N}=1,126$

Treatment and healthcare

Able to meet rheumatologist, $\mathrm{N}$ 721

Access to $\mathrm{GP}, \mathrm{N}=688$

$43(39.4)$

0.512

Including: Axial Spondyloarthritis, Rheumatoid Arthritis, Psoriatic Arthritis, Juvenile Idiopathic Arthritis, Gout and Peripheral Spondyloarthritis; ${ }^{2}$ Including: Systemic Lupus Erythematosus, Sjögren's Syndrome, Systemic Sclerosis and Myositis; ${ }^{3}$ Including: Polymyalgia Rheumatic and Vasculitis or Arteritis. 
arthritis ( $81.7 \%$ male vs $73.8 \%$ female). There was a higher prevalence of fibromyalgia among females (20\% vs $7.0 \%$ male). Overall, females reported worse self-perceived health $(67.0 \%$ vs $51.4 \%, \mathrm{p}<0.001)$, higher risk of anxiety $(59.5 \%$ vs $48.1 \%, p<0.001)$, and depression ( $48.0 \%$ vs $37.2 \%, p<0.001)$. Females reported a greater increase in smoking $(26.5 \%$ vs $17.5 \%, p=0.001)$, although they were less likely to drink alcohol ( $34.5 \%$ vs $25.4 \%, p=0.013)$, and also engaged less in physical activity $(53.0 \%$ vs $60.3 \%, p=0.045)$. Overall, females were more likely to keep their scheduled rheumatology appointment $(43.3 \%$ vs $34.1 \%$ of males $(p=0.049$; Table 1) with a higher proportion of females having their rheumatic treatment changed $(17.0 \%$ vs $10.7 \%, p=0.005)$.

Conclusion: The first wave of the COVID-19 pandemic and the containment measures have worsened self-perceived health status of patients with RMDs, affecting genders differently. Females reported worse psychological health and life habits such as increased smoking and reduced physical activity, while males increased their alcohol consumption and were less likely to attend their rheumatology appointments.

Acknowledgements: This study was supported by Novartis Pharma AG. We would like to thank all patients that completed the survey as well as all of the patient organisations that participated in the REUMAVID study including: the Cyprus League Against Rheumatism (CYPLAR) from Cyprus, the Association Française de Lutte Anti-Rhumatismale (AFLAR) from France, the Hellenic League Against Rheumatism (ELEANA) from Greece, the Associazione Nazionale Persone con Malattie Reumatologiche e Rare (APMARR) from Italy, the Portuguese League Against Rheumatic Diseases (LPCDR), from Portugal, the Spanish Federation of Spondyloarthritis Associations (CEADE), the Spanish Patients' Forum (FEP), UNiMiD, Spanish Rheumatology League (LIRE), Andalusian Rheumatology League (LIRA), Catalonia Rheumatology League and Galician Rheumatology League from Spain, and the National Axial Spondyloarthritis Society (NASS), National Rheumatoid Arthritis (NRAS) and Arthritis Action from the United Kingdom.

Disclosure of Interests: Marco Garrido-Cumbrera: None declared, Helena Marzo-Ortega Speakers bureau: AbbVie, Biogen, Celgene, Janssen, Lilly, Novartis, Pfizer, Takeda and UCB, Consultant of: AbbVie, Celgene, Janssen, Lilly, Novartis, Pfizer and UCB, Grant/research support from: Janssen and Novartis, Laura Christen Employee of: Novartis Pharma AG, Loreto Carmona: None declared, José Correa-Fernández: None declared, Sergio Sanz-Gómez: None declared, Pedro Plazuelo-Ramos: None declared, Souzi Makri Grant/research support from: Novartis, GSK and Bayer, Elsa Mateus Grant/research support from: Pfizer, grants from Lilly Portugal, Sanofi, AbbVie, Novartis, Grünenthal S.A., MSD, Celgene, Medac, Janssen-Cilag, Pharmakern, GAfPA., Serena Mingolla: None declared, KATY ANTONOPOULOU: None declared, LAURENT GRANGE: None declared, Clare Jacklin Grant/research support from: Abbvie, Amgen, Biogen, Eli Lilly, Gilead, Janssen, Pfizer, Roche, Sanofi \& UCB., Dale Webb Grant/research support from: AbbVie, Biogen, Janssen, Lilly, Novartis and UCB., Shantel Irwin: None declared, Victoria Navarro-Compán Grant/research support from: Abbvie, BMS, Janssen, Lilly, MSD, Novartis, Pfizer, Roche, and UCB DOI: 10.1136/annrheumdis-2021-eular.2417

\section{AB0678 RATES OF SURGICAL PROCEDURES OF THE KNEE AND HIP DURING THE "FIRST WAVE" OF COVID 19 IN SWEDEN}

A. Dell'isola ${ }^{1}$, A. Kiadaliri ${ }^{1}$, A. Turkiewicz ${ }^{1}$, V. Hughes ${ }^{1}$, K. Magnusson ${ }^{1,2}$ J. Runhaar ${ }^{3}$, S. M. A. Bierma-Zeinstra ${ }^{3}$, M. Englund ${ }^{1} .{ }^{1}$ Lund University, Clinical Epidemiology Unit, Orthopedics, Department of Clinical Sciences Lund, Lund, Sweden; ${ }^{2}$ Norwegian Institute of Public Health, Cluster for Health Services Research, Oslo, Norway; ${ }^{3}$ Erasmus MC, University Medical Center, Department of General Practice, Rotterdam, Netherlands

Background: Many countries imposed lockdowns in March 2020, in anticipation of the "first wave" of COVID-19 and the massive healthcare resources required to meet its acute medical needs. Sweden adopted a different strategy to contain the epidemic, opting for non-binding recommendations. Nonetheless, elective and acute surgical procedures in health care may have been affected.

Objectives: To investigate the effect of the "first-wave" of COVID-19 and the government's response in Sweden on the rates of total joint replacements (TJR), arthroscopies, and fracture surgeries of the knee and hip.

Methods: We used register data for the entire population of Skåne, the southernmost region in Sweden with 1.3 million inhabitants (13\% of the total Swedish population). We identified all residents aged $\geq 18$ years who between $1^{\text {st }}$ January 2015 and $31^{\text {st }}$ November 2020 underwent any of the following surgical procedures of the knee or hip: TJR (TJR due to fracture excluded), arthroscopy, and surgery due to fracture (including TJR). To demarcate pre-event and post-event periods, we established a differentiation point corresponding to mid-March 2020, the timepoint at which the the Swedish Public Health Agency began recommending social distancing, working from home, distance learning for secondary schools and universities, At the aggregate level, we modelled the number of surgeries per 10,000 adults from January 2015 up to September 2020. We did an interrupted time-series (ITSA) analysis using segmented ordinary least-squares regression to estimate changes in the levels and trends of surgical procedures compared to pre-COVID-19 levels, adjusting for seasonal variations. The month of March was treated as a "phase-in" period to give time for the new recommendations to be implemented. In addition we estimated the absolute and relative difference (with its $95 \%$ confidence interval $[\mathrm{Cl}]$ ) between the predicted and the counterfactual scenario in the monthly number of surgeries from April 2020, where the counterfactual is the rate of surgery that would have been expected if COVID-19 had not happened. To account for the possibility that other co-occurring events may be responsible for the observed changes, we assessed changes in the number of surgeries due to fractures, which are normally treated as emergencies that cannot be cancelled or rescheduled, and thus should be less affected, at least by policies at the hospital level.

Results: We identified a total of 20,831 TJRs, 12,156 arthroscopies and 15,041 fracture surgeries of the knee or hip over the study period. The monthly rate of surgeries and ITSAs are presented in Figure 1, with the pre-COVID period starting from February 2019 for readability (Figure 1). The results suggest that in April 2020 there was a decrease of $2.08(95 \% \mathrm{Cl} 1.81 ; 2.35)$ TJRs per 10,000 adults which corresponds to a decrease of $74 \%(95 \% \mathrm{Cl} 65 \% ; 85 \%)$ when compared to the counterfactual scenario. This was followed by a positive trend signifying a monthly increase of $0.36(95 \% \mathrm{Cl} 0.31 ; 0.40)$ TJRs per 10,000 adults. The rate of arthroscopies followed a similar pattern with a decrease of $0.55(95 \% \mathrm{Cl} 0.39 ; 0.71)$ arthroscopies per 10,000 adults in April, which corresponds to a $49 \%$ decrease $(95 \% \mathrm{Cl} 28 \%$; $63 \%)$ followed by a positive trend signifying a monthly increase of $0.11(95 \% \mathrm{Cl}$ $0.07 ; 0.15$ ) arthroscopies per 10,000 adults. The rate of surgery due to knee or hip fractures showed no decrease in April and was followed by a negative trend signifying a monthly decrease of $0.03(95 \% \mathrm{Cl} 0.002 ; 0.04)$ surgeries per 10,000 adults Conclusion: In Sweden, we observed a marked decrease in the number of typical elective knee and hip surgeries such as TJRs and arthroscopies, following the gov ernment's response to Covid-19. We then observed a slow but steady recovery that brought the rates of procedures towards expected levels by Fall 2020, before the "second wave" hit the country. The number of acute fracture surgeries showed no sharp drop, instead showing a steady and slow decline potentially due to reduction in commuting and in physical activities linked to recommendations of social

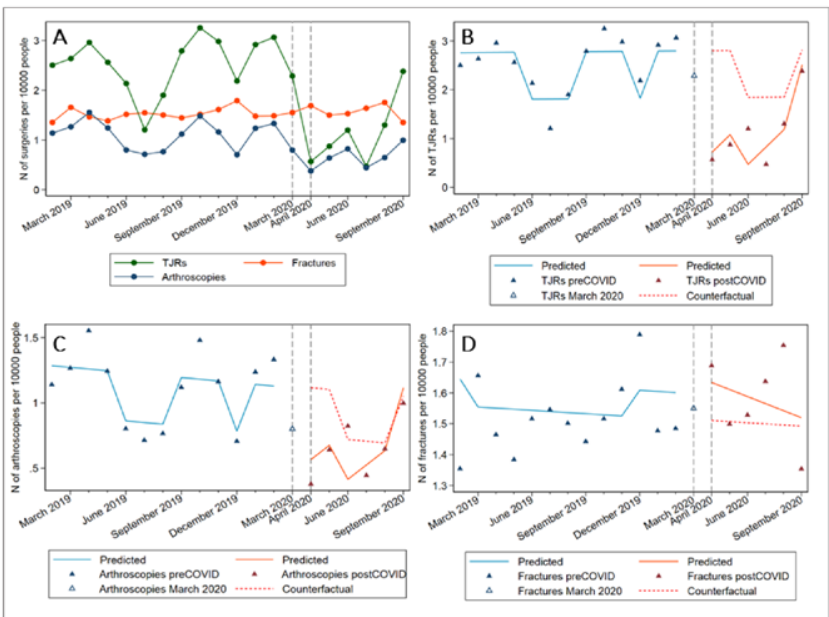

Figure 1: Monthly incidence of surgeries per 10,000 Skåne inhabitants aged $>18$

A: Monthly incidence for TJR, arthroscopies and fracture-related surgeries. Interrupted time series for TJR, C: arthroscopies, and D: fracture-related surgeries. Pre-COVID data is presented from February 2019 onwards for readability.

Disclosure of Interests: None declared

DOI: 10.1136/annrheumdis-2021-eular.2494

\section{AB0679 \\ NAILFOLD VIDEOCAPILLAROSCOPY RESULTS IN COVID-19 PATIENTS RECOVERED FROM DIFFERENT DISEASE SEVERITY}

E. Gotelli ${ }^{1}$, P. F. Bica ${ }^{1}$, T. Aloe', ${ }^{2}$ A. Sulli ${ }^{1}$, M. Grosso ${ }^{2}$, C. Pizzorni ${ }^{1}$, F. Cattelan ${ }^{1}$, S. Paolino ${ }^{1}$, E. Barisione ${ }^{2}$, V. Smith ${ }^{3}$, M. Cutolo ${ }^{1} .{ }^{1}$ Laboratory of Experimental Rheumatology and Academic Division of Clinical Rheumatology, Department of Internal Medicine and Specialties, University of Genova, IRCCS San Martino Polyclinic, Genova, Italy; ${ }^{2}$ Interventional Pneumology Unit, IRCCS San Martino Polyclinic, Genoa, Italy; ${ }^{3}$ Department of Rheumatology - Department of Internal Medicine - Unit for Molecular Immunology and Inflammation, VIB Inflammation Research Center (IRC), Ghent University Hospital, Ghent, Belgium

Background: COVID-19 is a multifaceted condition with a wide range of clinical manifestations, including microvascular/endothelial dysfunction, that starts in the early phase of the disease and may become dramatically harmful in the late stage, causing a massive pro-thrombotic state. Nailfold videocapillaroscopy (NVC) is the most used tool to identify microvascular status in a large spectrum 